\title{
Preparation and characterization of lamivudine microcapsules using various cellulose polymers
}

\author{
$\mathrm{K}_{\text {Prakash }}{ }^{1^{*}}, \mathrm{P} \mathrm{N} \mathrm{Raju}^{1}, \mathrm{~K} \mathrm{~K} \mathrm{Shanta}^{1}$ and M N Lakshmi ${ }^{2}$ \\ ${ }^{1}$ Sri Indu Institute of Pharmacy, Sheriguda, Ibrahimpatnam , R.R. Dist - 501510 \\ ${ }^{2}$ Centre For Biotechnology, Institute of Science and Technology, JNTU, Kukatpally, Hyderabad
}

\begin{abstract}
Purpose: The objective of the present study was to prepare and evaluate microcapsules for the controlled release of lamivudine using various cellulose polymers

Methods: The microcapsules were prepared by the solvent evaporation method. The prepared microcapsules were characterized for the percent drug content, entrapment efficiency, FTIR, DSC, scanning electron microscopy (SEM) and in vitro dissolution studies. Accelerated stability studies were also carried out.

Results: The microcapsules were spherical and free flowing. The entrapment efficiency was 76-86\%. The release of drug from the microcapsules extended up to 8 to 12 hours. FTIR and DSC thermograms showed the stable character of lamivudine in the microcapsules. SEM revealed that the microcapsules were porous in nature. The release kinetics study revealed that the prepared microcapsules were best fitted to the zero order for F-2, F-4 and F-5 formulations and Higuchi model, for F-1 and F-3 microcepsules

Conclusion: The release kinetics data and characteristion studies indicate that drug release from microcapsules was diffusion - controlled and that the micrapsules were stable..
\end{abstract}

Keywords: Lamivudine, cellulose polymers, microcapsules, controlled release, stability.

*Corresponding Author: E-mail pkatakam9@rediffmail.com, Phone No: +91-9848574488, 9885749484, 9347034999. 


\section{INTRODUCTION}

Acquired Immunodeficiency Syndrome (AIDS), which is now a plague in several countries, was first identified in California in 1981. It is a disease in which the body's immune system breaks down and is unable to fight off infections caused by human immunodeficiency virus (HIV). HIV infects human cells and uses the energy and nutrients provided by those cells to grow and reproduce and it is often necessary to take several medicines for prolonged periods. This problem is compounded especially for drugs having a shorter biological half life which have to be administered frequently. It is crucial for the success of AIDS therapy to maintain systemic drug levels consistently above its target antiretroviral concentration throughout the course of the treatment ${ }^{1,2}$. This can be achieved prolonging release.

Lamivudine is a synthetic nucleoside analog that is being increasingly used as the core of an antiretroviral regimen for the treatment of HIV infection. ${ }^{3,4}$ In vivo, nucleoside analogs are phosphorylated intracellularly by endogenous kinases to putatively active $5^{\prime}$ - triphosphate (3TC-TP) derivatives that prevent HIV replication by competitively inhibiting viral reverse transcriptase and terminating proviral DNA chain extension. ${ }^{5-7}$ Lamivudine is rapidly absorbed after oral administration with an absolute bioavailability of $86 \% \pm 16 \%$, peak serum concentration of lamivudine $\left(C_{\max }\right)$ of $1.5 \pm 0.5$ $\mathrm{mcg} / \mathrm{mL}$ and mean elimination half-life $\left(\mathrm{t}_{1 / 2}\right)$ of 5 to 7 hours, thus necessitating frequent administration to maintain constant therapeutic drug levels. ${ }^{8}$ Therefore, the objective of the present work is to provide a long acting pharmaceutical composition containing lamivudine in a modified release matrix formulation, to maintain the blood levels of the active ingredient for a prolonged period of time.

Only a limited study lamivudine extended release formulations has been carried out using ethyl cellulose ${ }^{9}$, Matrix tablets of anti-HIV drug didanosine ${ }^{10}$ have also been formulated.

\section{MATERIALS AND METHODS \\ Materials}

Lamivudine was obtained as a gift from Alkem laboratories Ltd (Mumbai, India). Cellulose acetate phthalate (CAP) was obtained from GM Chemicals, India, cellulose acetate butyrate $(C A B)$ was obtained from Eastman chemical company, USA, ethyl cellulose (EC) was obtained from The DOW chemical company, USA and hydroxy propyl methyl cellulose acetate phthalate (HPMCP) was obtained from SHIN-Etsu, Japan. All other chemicals and reagents used in the study were of analytical grade.

\section{Methods}

\section{Preparation of microcapsules}

Lamivudine microcapsules were prepared by the solvent evaporation method. The drug and polymer (1:1 ration) were dissolved or dispersed in acetone and added to heavy liquid paraffin with stirring. Microcapsules were recovered by treating with $\mathrm{n}$-hexane. The micro capsules prepared with CAP, CAB, EC, HPMCP and combination of CAP : $\mathrm{CAB}$ were coded as $\mathrm{F}-1$, $\mathrm{F}-2, \mathrm{~F}-3, \mathrm{~F}-4$ and $\mathrm{F}-5$ respectively. 
Table 1: Physical characteristics of microcapsules

\begin{tabular}{lccccc}
$\begin{array}{l}\text { Formulation code } \\
\text { Particle size distribution }\end{array}$ & F-1 & F-2 & F-3 & F-4 & F-5 \\
& \multicolumn{5}{c}{ Percent retained } \\
& & & & \\
\hline $10 / 20(1242 \mu)$ & $9 \pm 0.25$ & $6 \pm 0.29$ & $9 \pm 0.22$ & $12 \pm 0.21$ & $5 \pm 0.11$ \\
$20 / 30(666.5 \mu)$ & $77 \pm 1.96$ & $72 \pm 2.33$ & $78 \pm 1.78$ & $65 \pm 1.23$ & $81 \pm 2.63$ \\
$30 / 40(445 \mu)$ & $7 \pm 0.23$ & $2 \pm 0.19$ & $3 \pm 0.21$ & $9 \pm 0.21$ & $6 \pm 0.12$ \\
$60 / 80(225 \mu)$ & $7 \pm 0.22$ & $20 \pm 0.11$ & $11 \pm 0.37$ & $14 \pm 0.18$ & $8 \pm 0.22$ \\
\hline
\end{tabular}

Table 2: Accelerated stability data for lamivudine microcapsules at $40^{\circ} \mathrm{C} / 75 \% \mathrm{RH}$

\begin{tabular}{lccccc}
\hline Formulation code & F-1 & $\begin{array}{c}\text { F-2 } \\
\text { Drug content (\%) }\end{array}$ & F-3 & F-4 & F-5 \\
0 Month & 37.22 & 34.72 & 41.01 & 35.90 & 42.12 \\
1 Month & 36.33 & 34.22 & 40.12 & 34.99 & 41.22 \\
2 Months & 36.02 & 33.12 & 40.36 & 35.22 & 41.01 \\
3 Months & 35.22 & 33.34 & 40.21 & 35.12 & 40.12 \\
\hline
\end{tabular}

\section{Characterization of microcapsules Encapsulation efficiency (EE) ${ }^{11}$}

Drug loaded microcapsules (100 mg) were powdered and suspended in water and then sonicated (Power sonic 505, HWASHIN technology $\mathrm{co}$ ) for about 20 minutes. It was shaken for another (ORBITEX, Scigenics biotech) 20 minutes for the complete extraction of drug from the microcapsules. The mixture was filtered through a $0.45 \mu \mathrm{m}$ membrane filter (MILLIPORE). Drug content was determined by UV- visible spectrophotometer (Schimadzu, UV$1700 \mathrm{E} \mathrm{23}$ ) at $271 \mathrm{~nm}$. The percent entrapment was calculated using the Eq (1).

Encapsulation efficiency $=\begin{array}{ccc}\text { Actual drug content } \\ \text { Theoretical drug content }\end{array}$

\section{Particle size distribution}

Particle size analysis ${ }^{12}$ of the microcapsules was done by sieving method using Indian Standard Sieves \# 16, \#20, \#30, \#40, \#60 and \#80. The results of particle size distribution are given in the Table1.

Fourier Transforms Infrared Spectroscopy
(FT-IR) ${ }^{13}$ and Differential scanning calorimeter
(DSC) The FT-IR spectra acquired were taken from dried samples. An FT-IR (Thermo Nicolet 670) spectrometer was used for the analysis in the frequency range between 4000 and $400 \mathrm{~cm}-1$, and $4 \mathrm{~cm}-1$ resolution. The results are the means of 16 determinations. A quantity equivalent to $2 \mathrm{mg}$ of pure drug and drug loaded microcapsules were used.

Differential scanning calorimetry (DSC) study of drug loaded microcapsules was performed using a Diamond DSC (Mettler Star SW 8.10) to determine the drug excepient compatibility study. The analysis was performed at a rate $5^{\circ} \mathrm{C} \mathrm{min}{ }^{-1}$ from $50^{\circ} \mathrm{C}$ to $200^{\circ} \mathrm{C}$ temperature range under nitrogen flow of $25 \mathrm{ml} \mathrm{min}^{-1}$. 


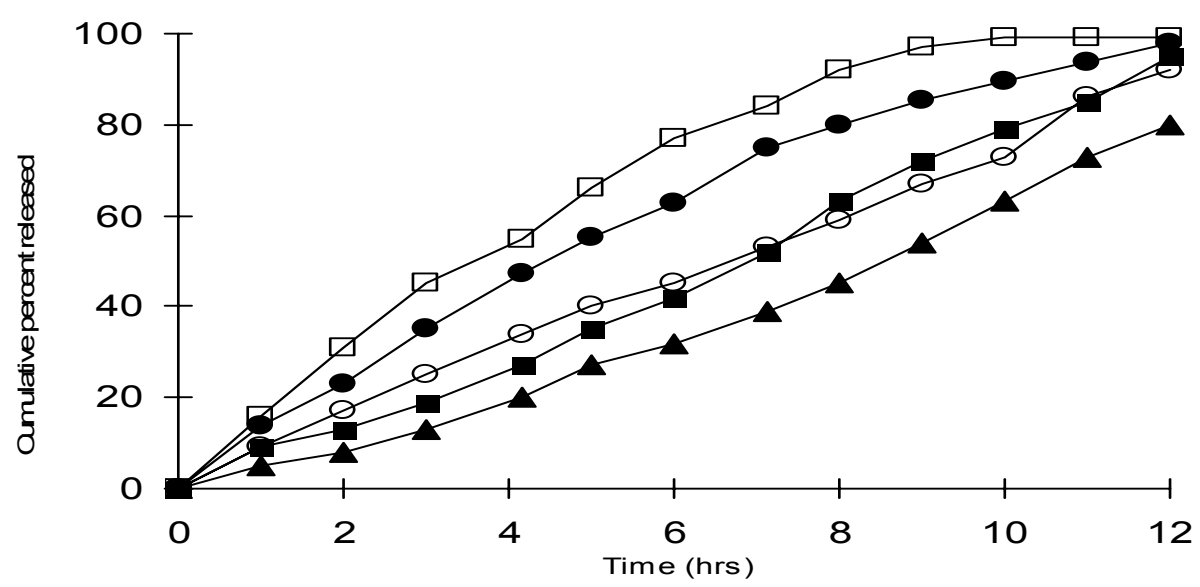

Fig 1: Cumulative \% release vs time plots of lamivudine microcapsules prepared with (- $\square-)$ with CAP, $(-\bullet-)$ with CAB, (-०-) with EC, (---) with HPMCP and combination of (-ム-) CAP: CAB

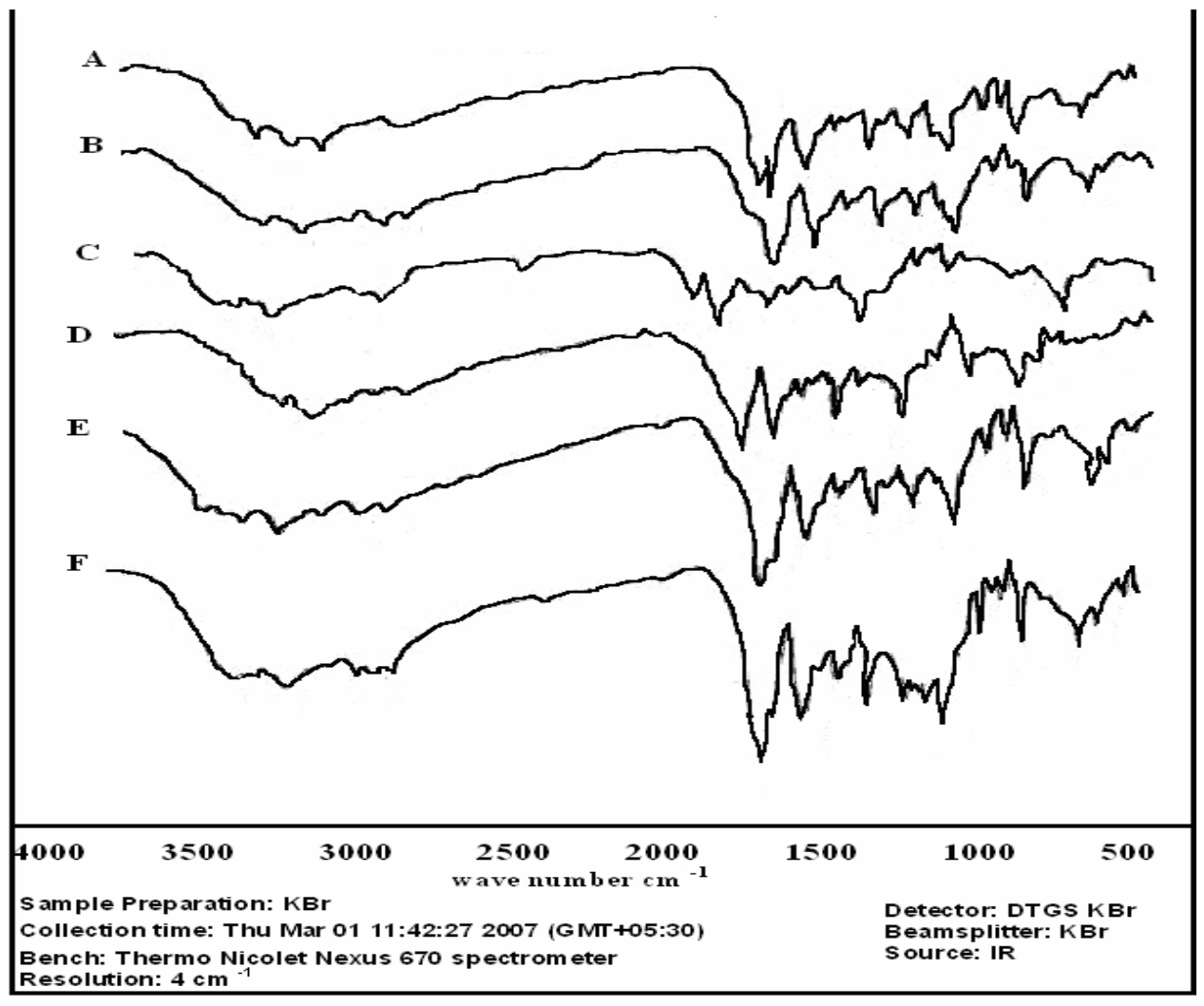

Fig 2: $\quad$ FT IR Spectra of pure (A) lamivudine, (B) CAP microcapsules (F-1), (C) CAB microcapsules (F-2), (D) EC microcapsule (F-3), (E) HPMCP microcapsule (F-4) and (F) combination of CAP:CAB (F-5) 
Prakash et al

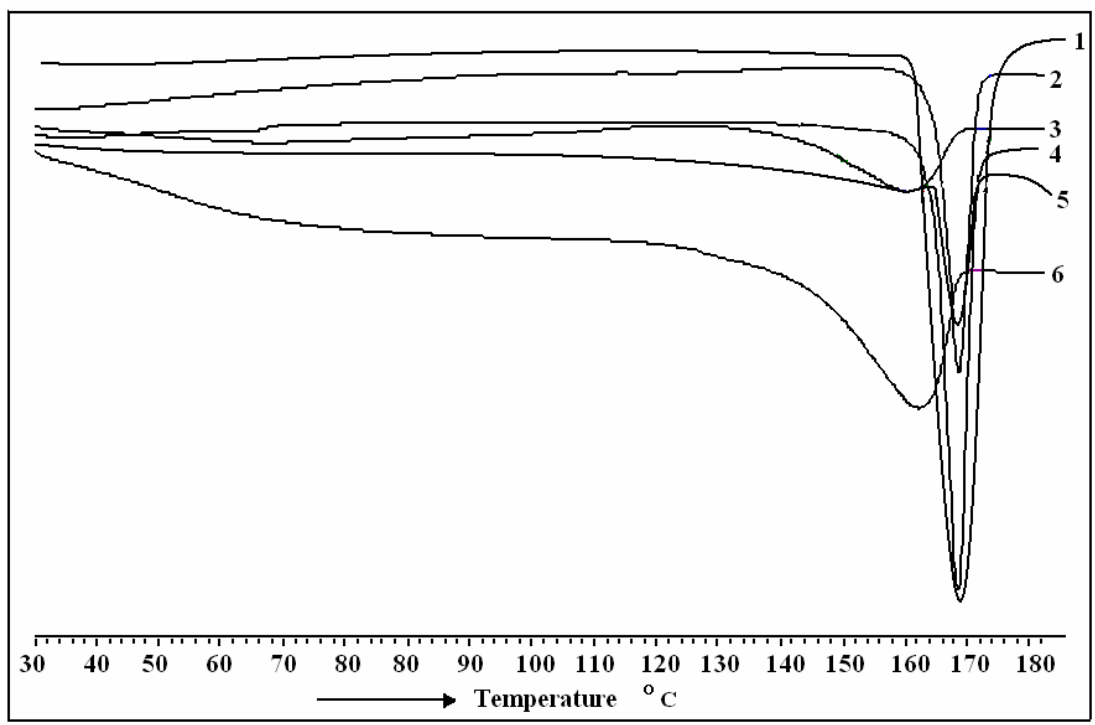

Fig 3: DSC thermo grams of lamivudine and lamivudine microcapsules with different polymers (1) Pure lamivudine (2) CAP (F-1), (3) CAB (F-2), (4) EC (F-3), (5) HPMCP (F-4) and (6) combination of CAP: CAB (F-5).

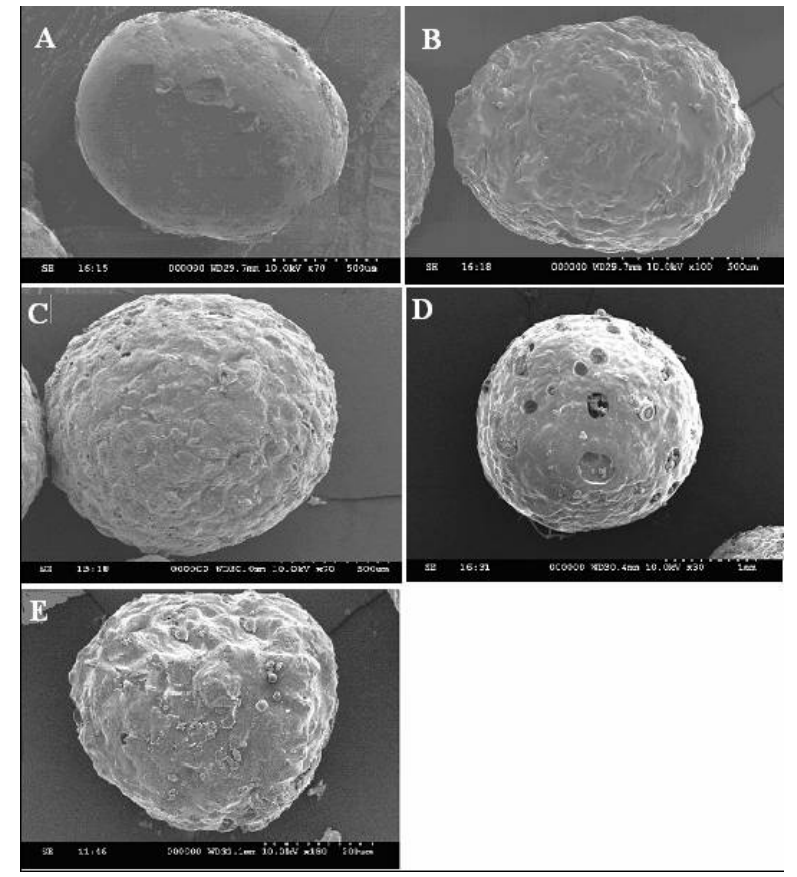

Fig 4: SEM photographs of (A) Cellulose acetate phthalate microcapsules (B) Cellulose acetate butyrate microcapsule (C) Ethyl cellulose microcapsules (D) Hydroxy propyl methyl cellulose phthalate microcapsules (E) Combination of Cellulose acetate Phthalate and Cellulose acetate butyrate 


\section{Scanning electron microscopy (SEM)}

Morphological characterization of the microcapsules was carried out scanning electron microscopy (JEOL JSM -5200). The samples were coated to $200 \mathrm{~A}^{\circ}$ thickness with goldpalladium using prior to microscopy.

\section{In Vitro Drug Release Studies}

In vitro dissolution studies were performed using USP type I dissolution apparatus (LABINDIA, DISSO-2000, Mumbai, India) at $75 \mathrm{rpm}$. The micro capsules were weighed and filled in the empty capsule shells and placed in the basket. The dissolution medium $(900 \mathrm{ml})$ consisted of $0.1 \mathrm{M}$ hydrochloric acid for the first 2 hours and then changed to phosphate buffer $\mathrm{pH} 7.4$ from 3 rd to 12 th hour, Temperature was maintained at $37^{\circ} \mathrm{C} \pm 5^{\circ} \mathrm{C}$. An aliquot $(5 \mathrm{~mL})$ was withdrawn at specific time intervals and rephenished with an equivalent volume of dissolution fluid. Drug content was determined by UV - visible spectrophotometer (Schimadzu, UV-1700 E 23) at $271 \mathrm{~nm}$. The release studies were conducted in triplicate and the results are showed in Fig1.

\section{Determination of stability of the microcapsules}

The microcapsules prepared in the present study were filled in the hard gelatin capsules ands stored in HDPE containers at $40^{\circ} \mathrm{C} / 75 \% \mathrm{RH}$ for 3 months as per $\mathrm{ICH}$ guidelines. The samples were then characterized for $\%$ drug content. The results are summarized in the Table 2.

\section{RESULTS}

Maximum release of lamivudine from the various formulations was achieved in $12 \mathrm{hrs}$ or longer, Figure1. The release mechanism of the lamivudine formulations was determined by comparing their respective correlation coefficients given in Table 1. Drug release from formulations $\mathrm{F}-1$ and $\mathrm{F}-3$ followed the Higuchi model but for F-2, F-4 and F-5 formulations, the release was best fitted to the zero order model. FTIR studies indicate four bands present in the lamivudine spectrum, namely; $\mathrm{N}-\mathrm{H}, \mathrm{O}-\mathrm{H}, \mathrm{C}=\mathrm{O}$, $\mathrm{C}=\mathrm{N}$ linkages respectively. The same bands were also found in the spectra of the formulations, showing that no drug-polymer interaction occurred (see Figure2). DSC thermogram of pure lamivudine showed a sharp endothermic peak at $180^{\circ} \mathrm{C}$. The thermograms of the formulations F-1 to F-5 also showed a similar the same endothermic peak at $180^{\circ} \mathrm{C}$. This further confirms that there was no drug polymer interaction. Scanning electron microscopy (SEM) results (Figure4) show that the microcapsules were spherical and that the microcapsules prepared with cellulose acetate phthalate (CAP) had a formed smooth surface. The results of all the formulations were found good. High entrapment efficiency was observed in the microcapsules prepared with ethyl cellulose and combination of cellulose acetate phthalate and cellulose acetate butyrate. The results of accelerated stability study on the microcapsules (shown in Table 1) revealed a good correlation between the original and the aged samples.

\section{DISCUSSION}

The formulations either followed zero order release or the Higuchi release model. Thus drug release was diffusion controlled. The release mainly deepened on the type of polymer and viscosity. The results indicate that F-5, formulations showed the slowest release rate while FTIR indicated that there was no drugpolymer interaction. This was further confirmed by the DSC results. The results of accelerated stability study showed the stable nature of the drug. A good entrapment efficiency was observed. SEM demonstrated the spherical nature of the microcapsules and the presence of drug particles on their surface.

\section{CONCLUSION}

The lamivudine microcapsules prolonged drug release for 12 hours or longer. Would be capable of reducing the frequency of administration and the dose-dependent side effects associated with the repeated administration of conventional lamivudine tablets. No drug polymer interaction was found and lamivudine remained stable over a long period of time.

\section{ACKNOWLEDGEMENT}

The authors greatly acknowledged the Alchem Laboratories, Mumbai, India, for the gift of lamivudine. The authors are grateful to the 
Indian Institute of Chemical Technology, Hyderabad, India for help in performing the characterization studies.

\section{REFERENCES}

1. Chien YW, Wearley LL. AIDS and chemotherapy. Drugs Today. 1989;25:19-25.

2. Jain $S$, Umamaheshwari $R B$, Bhadra $D$, Jain $N K$. Ethosomes: a novelvesicular carrier for enhanced transdermal delivery of an anti-HIV agent.Ind J Pharm Sci. 2004;66:72-81.

3. Katlama $C$, ValantinMA,Matheron $S$, Coutellier $A$, Calvez $V, D$ Descamps $D$, Longuet $C$, Bonmarchand M, Tubiana R, De Sa M, Lancar R, Agut $H$, Brun-Vezinet $F$, and Costagliola $D$. Efficacy and tolerability of stavudine plus lamivudine in treatment-naive and treatment experienced patients with HIV-1 infection. Ann Intern Med. 1998;129:525-531.

4. Merrill DP, Moonis M, Chou TC, Hirsch MS. Lamivudine or stavudine in two- and three-drug combinations against human immunodeficiency virus type 1 replication in vitro. J Infect Dis. 1996; 173:355364.

5. Furman PA, Fyfe JA, St Clair MH, Richards CA, Spector T. Phosphorylation of 3'-azido-3'-eoxythymidine nd selective interaction of the 5'-triphosphatewith human immunodeficiency virus reverse ranscriptase.Proc Natl Acad Sci USA. 1986;83:8333-8337.

6. Katy H. P. Moore; Jo E. Barrett; Shuching Shaw; Gary E. Pakes; Richard Churchus; Anu Kapoor; Judy Lloyd; Michael G. Barry; David Back. The pharmacokinetics of lamivudine hosphorylation in peripheral blood mononuclear cells from patients infected with HIV-1. AIDS. 1999;13:2239-2250.
7. Becher F; Landman R; Mboup S; NdeyeToure Kane C; Canestri A; Liegeois F; Vray M; Prevot M H; Leleu $G$; Benech H. Monitoring of didanosine and stavudine intracellular trisphosphorylated anabolite concentrations in HIV-infected patients. AIDS 2004;18:181-187.

8. Himadri sen, Surva Kumar J, inventors. Long acting composition containing zidovudine and Lamivudine. US patent publication US 20050175694A1. August 11, 2005.

9. Amitava G, Udaya Kumar N, Partha R, Development, evaluation and method selection for the preparation of lamivudine microspheres, The Int $\mathrm{J}$ Pharmacy, Pharmacy on-line, www.priory.com, First published June 2007.

10. Sanchez-Lafuente C, Furlanetto S, Fernandez-Arevalo M, Alvarez-Fuentes J, Rabasco AM, Faucci MT, Pinzauti S, Mura P.Didanosine extended release matrix tablets: optimization of formulation variables using statistical experimental design. Int J Pharm. 2002; 237:107-118.

11. Gohel M.C, Parik R.K, Amin A.F and Surati A.K. Preparation and formulation optimization of sugar crosslinking gelatin microspheres of diclofenac sodium. Indian J Pharm Sci 2005; 67: 575-581

12. Indian Pharmacopoeia. (1996) 5th ed. Controller of Publication. 328-329,393-395.

13. Bhumkar D.R, Maheshwari M, Patil V.B and Pokharkar $V . B$. Studies on effect of variables by response surface methodology for naproxen microspheres. Indian Drugs 2003; 40: 455-461 